Atıf İçin: Pıhtılı G, Torğut G, 2021. P(ع-CL-co-MMA)/Montmorillonit Kompozitlerinin Sentezi, Karakterizasyonu ve Elektriksel Empedans Analizör Uygulamaları. Ĭgdır Üniversitesi Fen Bilimleri Enstitüsü Dergisi, 11(3): $2160-2172$.

\title{
P(E-CL-co-MMA)/Montmorillonit Kompozitilerinin Sentezi, Karakterizasyonu ve Elektriksel Empedans Analizör Uygulamaları
}

\author{
Güzin PIHTILI ${ }^{1 *}$, Gülben TORĞUT ${ }^{2}$
}

ÖZET: Bu çalışmada -Poli-(ع-CL-co-MMA) kopolimeri sentezlenerek, bu polimerin kompozitleri hazırlanmıştır. Metil metakrilat monomeri, 2 kollu makrobaşlatıcı olan -Poli- $\left(\boldsymbol{\varepsilon}-\mathrm{CL}-\mathrm{NCl}_{2}\right)$ varlığında ATRP metoduyla polimerleştirilmiştir. Sentezlenen kopolimerin \%3, \%6 ve \%15 oranlarında bir montmorillonit olan bentonit ile kompozitleri hazırlanmış ve polimer içindeki dağılımları incelenmiştir. Kompozitler dispers etme yöntemi ile gerçekleştirilmiştir. Kopolimerin yapısı FT-IR, ${ }^{1} \mathrm{H}-\mathrm{NMR}$, DSC, TGA ve SEM analiz yöntemleri ile karakterize edilmiştir. Empedans analizör cihazı ile polimer/MMT kompozitlerinin farklı elektriksel özellikleri araştırıldı. Bu sebeple, kopolimerlerin üzerindeki montmorillonitin etkisi elektriksel olarak frekans ve sıcaklığa bağlı olarak incelendi. Kil ile hazırlanmış kopolimerlerin elektriksel özelliklerinin, katkısız polimere göre daha yüksek değerlerde çıktığı gözlenmiştir.

Anahtar Kelimeler: montmorillonit, bentonit, polimer/kil kompozitleri, elektriksel özellik

\section{Synthesis, Characterization and Electrical Impedance Analyzer Applications of P(E-CL-co- MMA)/Montmorillonite Composites}

\begin{abstract}
In this study, Poly(E-CL-co-MMA) was synthesized and its composites have been prepared. Methyl methacrylate monomer was polymerized by the ATRP method in the presence of twoarmed macroinitiator Poly $\left(\varepsilon-\mathrm{CL}-\mathrm{NCl}_{2}\right)$. The composites of the copolymer were prepared with bentonite, which is a montmorillonite rate of $3 \%, 6 \%$ and $15 \%$ and their dispersion in the polymer was examined. Composites are prepared by dispersing method. The structure of the copolymer was characterized by FT-IR, ${ }^{1} \mathrm{H}-\mathrm{NMR}, \mathrm{DSC}$, TGA and SEM anaylsis methods. Different electrical properties of polymer / MMT composites were investigated with impedance analyzer device. Therefore, the effect of montmorillonite on the copolymers was examined depend on the frequency and temperature as electrical. It was observed that electrical properties of polymers prepared with clay were higher than pure polymer.
\end{abstract}

Keywords: montmorillonite, bentonite, polymer/clay composites, electrical property

${ }^{1}$ Güzin PIHTILI (Orcid ID: 0000-0003-2261-6810), Munzur Üniversitesi, Pertek Sakine Genç MYO, Tıbbi Hizmetler ve Teknikler Bölümü, Tunceli, Türkiye

${ }^{2}$ Gülben TORĞUT (Orcid ID: 0000-0003-1730-1152), Munzur Üniversitesi, Tunceli MYO, Otel, Lokanta ve İkram Hizmetleri Bölümü, Tunceli, Türkiye

*Sorumlu Yazar/Corresponding Author: Güzin PIHTILI, e-mail: gpihtili@munzur.edu.tr 


\section{GİRIŞ}

Polimerler her geçen gün hem ticari olarak hem de bilimsel açıdan ilgi odağı olan, makromoleküler kimyanın önemli yapılarındandır (Biryan, 2019). Polimer/kil kompozitleri, organik polimer matrisler ve nano ölçekli organofilik kil dolgu maddelerinden oluşan bir hibrit malzeme sınıfıdır. Doğadaki kil mineralleri silika bakımından zengindirler ve kil tabakaları arasında $\mathrm{Al}^{+3}, \mathrm{Mg}^{+2}, \mathrm{Fe}^{+2}, \mathrm{Ca}^{+2}$ ve $\mathrm{Na}^{+}$ iyonları bulunmaktadır (Çankaya ve Sökmen, 2016). Montmorillonitin ideal formülü $\mathrm{Si}_{8-\mathrm{x}} \mathrm{Al}_{\mathrm{x}}+\mathrm{Al}_{4-\mathrm{y}}+$ $\mathrm{Mg}_{\mathrm{y}}(\mathrm{Fe})+\mathrm{O}_{20}(\mathrm{OH})_{4 \mathrm{n}} \mathrm{H}_{2} \mathrm{O}$ olarak verilir. Nano ölçekli killerden olan montmorillonit (MMT), oldukça ilgi çekicidir ve geniş çapta incelenmiştir. MMT, kenar paylaşımlı oktahedral bir alüminyum hidroksit tabakasına kaynaşmış iki silika tetrahedral tabakadan oluşan hidratlanmış alümina-silikat katmanlı bir kildir. Yüksek yüzey alanı, geniş en-boy oranı (50-1000) ve 10 A'lık trombosit kalınlığı birçok araştırma için uygun bir madde olma özelliğindedir (Xu ve ark., 2006). Smektit grubunun bir türü olan MMT nin otomobil sanayisi, inşaat sektörü, devrelerde, gıda endüstrisi, gibi çok önemli kullanım alanları bulunmaktadır (Alparslan, 2013). Bentonit yer kabuğunda bol miktarda bulunan, sarı, siyah ve gri renklerden oluşan bir kildir. Temel mineral olarak smektit grubundan olan, montmorillonitten oluşan ve bunun yanı sıra kuvars, kalsit, feldispat, alçıtaşı, dolomit, muskovit, plajiyoklaz, demirli bileşikler ve biyotit gibi diğer mineralleri de içeren bir kildir. Suda şişer ve çok çeşitli metalleri ve diğer mineralleri kolaylıkla emme özelliği bulunmaktadır (Ravindra ve ark., 2017). Kil-polimer nanokompozitlerinde dağıtıcı faz polimerdir, destek maddesi ise kildir. Kompozit sistemleri katkısız polimerlere göre şişme, adsorpsiyon, plastiklik ve reolojik gibi birçok fiziksel ve kimyasal üstün özelliklere sahip olurlar (Çalımlı, 2010). Polimerlerin modifiye edilmiş mineraller ve killer ile blendlerinin hazırlanmasının yanında, polimer/kil kompozitleri ile ilgili çalışmalar son yıllarda önemli derecede hız kazanmıştır (Usuki ve ark., 1993; Giannelis, 1996).

Dielektrikler yalıtkan malzemelerdir (Tareev, 1975; Neamen, 1997) ve dış elektrik alanın etkisinde kaldıkları zaman enerji ya da yük depolayabilme özelliğine sahip olurlar (Symth, 1955). Dielektrik sabiti bir malzemedeki, polarizasyonun derecesini göstermektedir ve polimerlerin en önemli özelliklerinden biridir (İyibakanlar ve Oktay, 2007). Yüksek dielektrik özelliğe sahip polimer bazlı kompozitlerin, mikrodalga iletişim cihazları, yapay kaslar mikro elektromekanik sistemler için gömülü kapasitör olabilme gibi uygulamalara sahiplerdir (Yang ve Kofinas, 2007).

$\mathrm{Bu}$ çalışmada inorganik yapılı dolgunun polimer matrisi içinde homojen olarak dağılması ile polimer/MMT sisteminin ölçülen özelliklerinin iyi bir performansa ulaşmasını amaçladık. Sentezlenen kopolimerin karakterizasyonu FT-IR, ${ }^{1} \mathrm{H}-\mathrm{NMR}$ ile yapılmış, TGA ve DSC ile termal kararlılı̆̆ 1 ve SEM ile kompozitlerin yüzey morfolojileri incelenmiştir. Empedans analizör cihazı ile polimer /kompozitlerin dielektrik ve iletkenlik özelliklerindeki değişimler araştırılmıştır.

\section{MATERYAL VE YÖNTEM}

\section{Materyal}

$\varepsilon$-kaprolakton, metil metakrilat monomeri, bentonit, $\mathrm{CuBr}, 2,2^{\prime}$-bipridin ve Tetrahidrofuran (THF) Sigma firmasından satın alınarak temin edilmiştir. 2,2'-azobisizobütironitril (AIBN), kloroformda kristallendirilerek başlatıcı olarak kullanılmıştır. Çalışmada kullanılan diğer tüm kimyasallar başka bir işlem yapılmadan alındığı şekilde kullanılmıştır.

\section{Cihazlar}

Kopolimerlerin FT-IR spektrumları; 4000- $400 \mathrm{~cm}^{-1}$ aralığında Perkin Elmer Spectrum One FTIR spektrometresi ile, ${ }^{1} \mathrm{H}-\mathrm{NMR}$ spektrumu ise Bruker Avance III-400 cihazı kullanılarak kaydedilmiştir. Polimerlerin DSC ölçümleri için SHIMADZU marka DSC-50 ve TGA eğrileri için SHIMADZU marka 
TGA-50 termobalans sistemi kullanılmıştır. Poli(E-CL-co-MMA) ve kompozitlerin dielektrik ve iletkenlik değerleri Quadtech 7600 Precision LCR meter Empedans Analizör cihazı ile incelenmiştir. SEM analizleri ise, Hitachi S-3500 marka taramalı elektron mikroskobu ile gerçekleştirilmiştir.

\section{ATRP Metodu ile Poli(E-CL-co-MMA) Kopolimerinin Sentezi}

Bu çalışmada kullanılan makrobaşlatıcı, önceki çalışmamızda (Pihtili ve ark., 2020) sentezlenen ve karakterize edilen Poli( $\varepsilon$-kaprolakton- $\left.\mathrm{NCl}_{2}\right)$ polimeridir. Poli( $\varepsilon$-kaprolakton- $c o$-metilmetakrilat); [P(ع-CL-co-MMA)] kopolimeri ATRP metodu ile hazırlanmıştır. Polimerizasyon tüpüne ilk önce katalist sistem oluşturmak için $\mathrm{CuBr}(0.006 \mathrm{~g}, 0.000041 \mathrm{~mol})$ ve 2,2'-bipridin (0.012 g, $0.000076 \mathrm{~mol})$ eklendi. Karışım 10 dakika argon gazından geçirildi ve daha sonra $\mathrm{P}\left(\varepsilon-\mathrm{CL}-\mathrm{NCl}_{2}\right)$ makrobaşlatıcısı $(0.15$ g, $0.000024 \mathrm{~mol}), 10 \mathrm{~mL}$ THF içinde çözülerek katalist sisteme eklendi. Elde edilen karışım üzerine metil metakrilat monomeri $(1 \mathrm{~g}, 0.01 \mathrm{~mol})$ ilave edildi ve terkrar argon gazından 10 dakika geçirilerek ortamın inert olması sağlandı. Polimerizasyon tüpü önceden $120{ }^{\circ} \mathrm{C}$ sıcaklığa ayarlanmış yağ banyosuna daldırılarak kopolimerizasyon başlatıldı ve 24 saat sonra sonlandırıldı. Viskoz haldeki polimer diklormetanda çözülerek, etil alkol içinde çöktürüldü. Saflaştırmak için etil alkolde çöktürme işlemi iki kez tekrarland 1 ve edilen kopolimer vakum altında $40{ }^{\circ} \mathrm{C}^{\prime} \mathrm{de} 24$ saat kurutuldu. Reaksiyon şeması Şekil 1 'de verilmiştir.
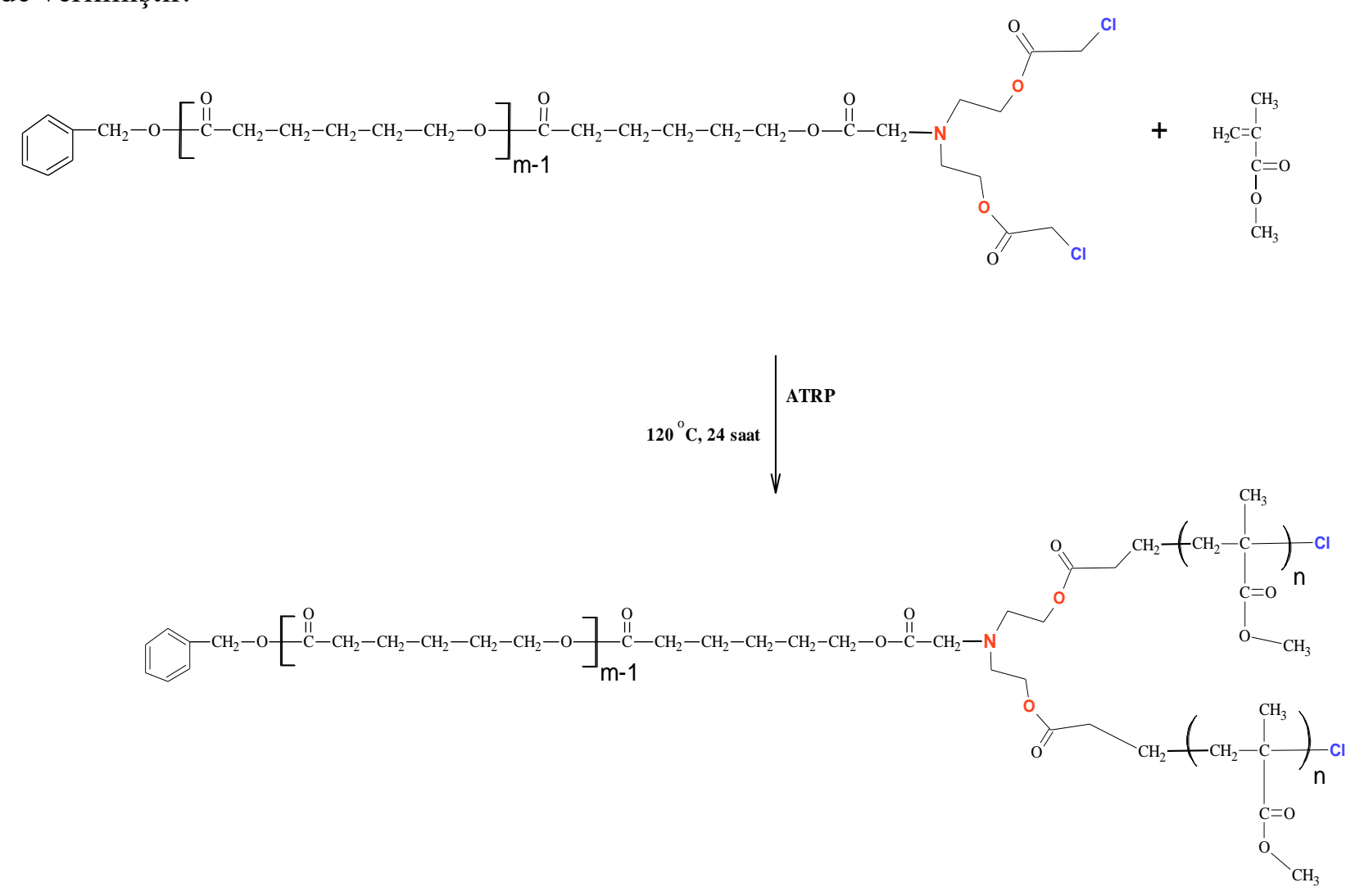

Şekil 1. P(E-CL-co-MMA) kopolimerinin sentezi

\section{Polimer/ Montmorillonit (Bentonit) Kompozitlerinin Hazırlanması}

$\mathrm{P}(\varepsilon-C L-c o-M M A)$ kopolimeri $5 \mathrm{~mL}$ THF çözeltisi içerisinde çözülmüştür. Kütlece \%3, \%6, \%15 oranlarda alınan ve parçacık boyutu $\leq 25 \mu \mathrm{m}$ olan montmorillonit polimer çözeltisi içine ilave edildi ve karışım 1 saat ultrasonik banyoda karıştırıldı. Daha sonra homojenizatör (sanikatör) yardımı ile montmorillonitin polimer içinde homojen olarak dağılması sağlandı. Polimer/MMT karışımı petri kabı 
içine döküldü ve çözücüsü uzaklaştırıldı. Elde edilen polimer film $45{ }^{\circ} \mathrm{C}^{\prime}$ de vakum altında 24 saat kurutulmuştur. Polimer/kompozitlerinin hazırlanması Şekil 2'de şematik olarak verilmiştir.

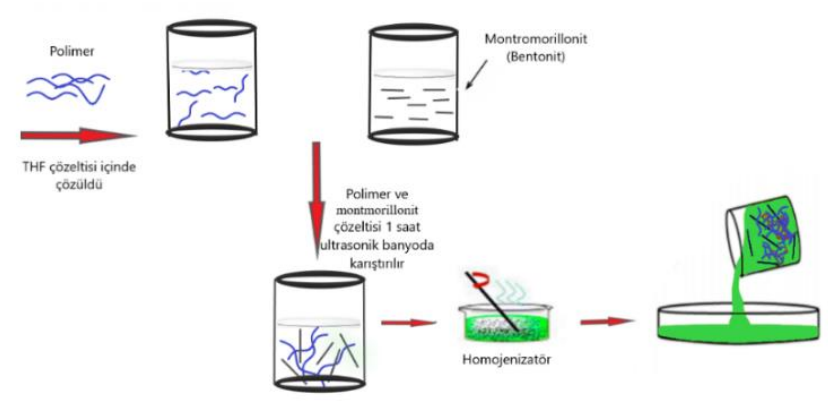

Şekil 2. $\mathrm{P}(\varepsilon-\mathrm{CL}-c o-\mathrm{MMA}) / \mathrm{MMT}$ kompozit üretimi

\section{BULGULAR VE TARTIŞMA}

\section{$\mathrm{P}(\varepsilon-C L-c o-M M A)$ ve $\mathrm{P}\left(\varepsilon\right.$-CL-co-MMA)/ $\mathrm{MMT}^{\prime}$ in FT-IR ve ${ }^{1} \mathrm{H}-\mathrm{NMR}$ Spektroskopisi ile Karakterize Edilmesi}

$\mathrm{P}(\varepsilon$-CL-co-MMA), $\mathrm{P}(\varepsilon$-CL-co-MMA)/3\% MMT, $\mathrm{P}(\varepsilon$-CL-co-MMA) $/ 6 \%$ MMT ve $\mathrm{P}(\varepsilon$-CL-coMMA)/15\% MMT polimerlerinin FT-IR spektrumları Şekil 3' de verilmiştir. 3002 ve $2951 \mathrm{~cm}^{-1 \prime}$ de alifatik C-H gerilmeleri, $1731 \mathrm{~cm}^{-1 \prime}$ de $\varepsilon$-kaprolakton halkasındaki ve MMA birimindeki ester karboniline ait gerilme titreşimi $(-\mathrm{C}=\mathrm{O}), 1497-1470 \mathrm{~cm}^{-1}$ ' deki pikler ise alifatik $\mathrm{C}-\mathrm{H}$ eğilme (rock) titreşimine ait olan piklerdir. Ayrıca bentonit partiküllerinin $\left[\mathrm{Ca} / \mathrm{Na}(\mathrm{Al}, \mathrm{Fe}, \mathrm{Zn})_{2}(\mathrm{Al}, \mathrm{Si})_{4} \mathrm{O}_{10}(\mathrm{OH})_{2}\right.$ $\mathrm{nH}_{2} \mathrm{O}$ ] varlığını gösteren bantlardan; $3625 \mathrm{~cm}^{-1}$ ' de gözlenen çok keskin tek bant ve $3445 \mathrm{~cm}^{-1}$ ' de geniş bant olan $\mathrm{OH}$ gerilme piki spektrumda görülmektedir. Düşük bölge 1387, 1105, 1030, 1007, 914, 787, 698, 540, 468, $432 \mathrm{~cm}^{-1}$ bantları $\mathrm{SiO}_{4}$ tetrahedron titreşimi sonucu oluşan piklerdir. 1032 ve $1010 \mathrm{~cm}^{-1}$ de maksimum absorpsiyonlu keskin bandın iki bileşeni, katmanlı silikat montmorillonit mineralinin bir özelliğidir ve üçlü dejenere Si-O germe $v_{3}{ }^{\prime} \mathrm{e}$ aittir. $538 \mathrm{~cm}^{-1}$ ' deki pik; Al-O-Si grubunun varlığını gösterir. Şekil 4'te verilen ${ }^{1} \mathrm{H}-\mathrm{NMR}$ spektrumuna göre $(\delta / \mathrm{ppm})(\mathrm{DMSO}) ; 4.01 \varepsilon$-CL birimlerindeki $\mathrm{OCH}_{2}$ protonlar1, 3.59 MMA birimleri, at $2.38 \varepsilon$-CL birimlerindeki $-\mathrm{C}=\mathrm{O}$ 'e komşu protonlar, 1.3-1.8 ana zincirdeki $-\mathrm{CH}_{2}$ ve $\mathrm{CH}_{3}$ protonlarının varlığ 1 yapıyı desteklemektedir.

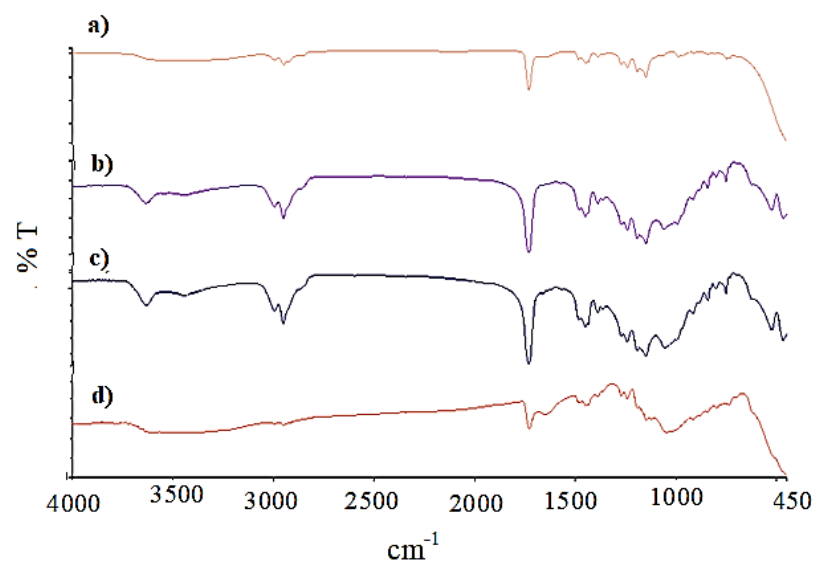

Şekil 3. FT-IR Spektrumları a) $\mathrm{P}(\varepsilon$-CL-co-MMA), b) $\mathrm{P}(\varepsilon$-CL-co-MMA)/3\% MMT, c) $\mathrm{P}(\varepsilon$-CL-co-MMA)/6\% MMT, d) P( $\varepsilon$-CL-co-MMA)/ 15\% MMT 


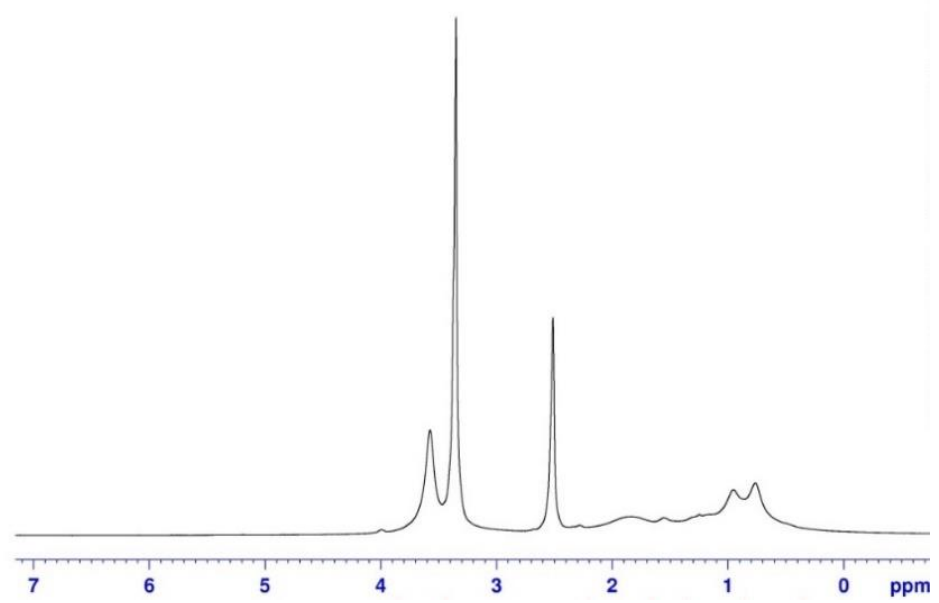

Şekil 4. $\mathrm{P}\left(\varepsilon\right.$-CL-co-MMA) polimerinin ${ }^{1} \mathrm{H}-\mathrm{NMR}$ spektrumu

\section{Polimerlerin Termal Analiz Ölçümleri}

$\mathrm{P}(\varepsilon$-CL-co-MMA) ve $\mathrm{P}(\varepsilon$-CL-co-MMA)/3-6-15\%MMT kompozitlerinin camsı geçiş sıcaklıkları $\left(\mathbf{T}_{g}\right)$; DSC termogramlarından, termal bozunmaları ise Termogravimetrik analiz ile belirlenmiştir. Yaklaşı 5-6 mg miktarında alınan kopolimer ve polimer/MMT kompozit numuneleri $\mathrm{N}_{2}$ gazı ortamında $20{ }^{\circ} \mathrm{C} / \mathrm{dk}$ sitma hiziyla $200{ }^{\circ} \mathrm{C}^{\prime}$ ye kadar ssitılarak DSC termogramları, $10{ }^{\circ} \mathrm{C} / \mathrm{dk}$ sitma hiziyla $500{ }^{\circ} \mathrm{C}^{\prime}$ ye kadar ısıtılması ile de TGA eğrileri kaydedilmiştir. Termal bozunmaları incelemek amacı ile TA-50 sistemi kullanıldı. $\mathrm{P}(\varepsilon$-CL-co-MMA) ve $\mathrm{P}(\varepsilon$-CL-co-MMA)/3-6-15\%MMT kompozitlerinin camsı geçiş sıcaklıkları $\left(\mathrm{T}_{g}\right)$ Şekil $5^{\prime}$ de verilmiş̧tir. DSC termogramlarında, $61-68^{\circ} \mathrm{C}$ arasında görülen camsı geçiş sıcaklıkları, $\varepsilon$-kaprolakton biriminin varlığını koruduğunu göstermektedir. $\mathrm{P}(\varepsilon$-CL-co-MMA) kopolimerinin camsı geçiş sıcaklığı $105^{\circ} \mathrm{C}$ olarak okunmuştur. $\mathrm{P}(\varepsilon$-CL-co-MMA)/3\% MMT, P( $\varepsilon$-CLco-MMA)/ 6\%MMT ve $\mathrm{P}(\varepsilon-\mathrm{CL}-c o-\mathrm{MMA}) / 15 \% \mathrm{MMT}^{\prime}$ nın ise $\mathrm{T}_{g}{ }^{\prime}$ leri sirası ile; 110,119 ve $125^{\circ} \mathrm{C}$ olarak belirlenmiştir. Saf kopolimerin camsı geçiş sıcaklığına göre, kompozitlerin $\mathrm{T}_{g}{ }^{\prime}$ lerinin artan MMT partikülleri ile arttığ gözlenmiştir. Montmorillonitin kopolimerin $\mathrm{T}_{g}$ sıcaklığının üstündeki sıcaklık noktalarında kompozit yapının etrafında bir karbon tabakası oluşturmuş olabileceğini ve böylelikle camsı geçiş sıcaklığını arttırdığını söyleyebiliriz (Güven, 2010). Bununla birlikte, montmorillonitin, polimerin serbest hacmini azaltarak camsı geçiş sıcaklığını arttırdığını da söylemek mümkündür. $\varepsilon$-CL, MMA birimlerine göre kristal bölge varlığını korumuş ve bir faz farkının oluştuğunu göstermiştir.

Polimerlerin termal stabilitesini incelemek için, oda sıcaklığından $500^{\circ} \mathrm{C}$ ye azot gazı altında 10 ${ }^{\circ} \mathrm{C} / \mathrm{dk}$ 1sıtma hızında kaydedilen termogravimetrik eğriler Şekil 6' da gösterilmiş ve sonuçlar Çizelge 1 'de özetlenmiştir. P(e-CL-co-MMA) kopolimerinin ve montmorillonit yüzdesine bağl olarak kompozitlerin bozunmaya başlama sıcaklıkları $306^{\circ} \mathrm{C}$ ile $340{ }^{\circ} \mathrm{C}$ arasında değişmiştir. Termogramlar, kopolimerlerin ayrışmasının tek basamakta meydana geldiğini açıkça göstermiştir. $500{ }^{\circ} \mathrm{C}$ 'de kopolimerdeki kalıntı \%2 ile \%58 arasındadır. Bentonit miktarı arttıkça, \% atık miktarı da artmıştır. Buda montmorillonitin (bentonitin) çalışılan sıcaklık aralığında bozunmadığını göstermektedir. 


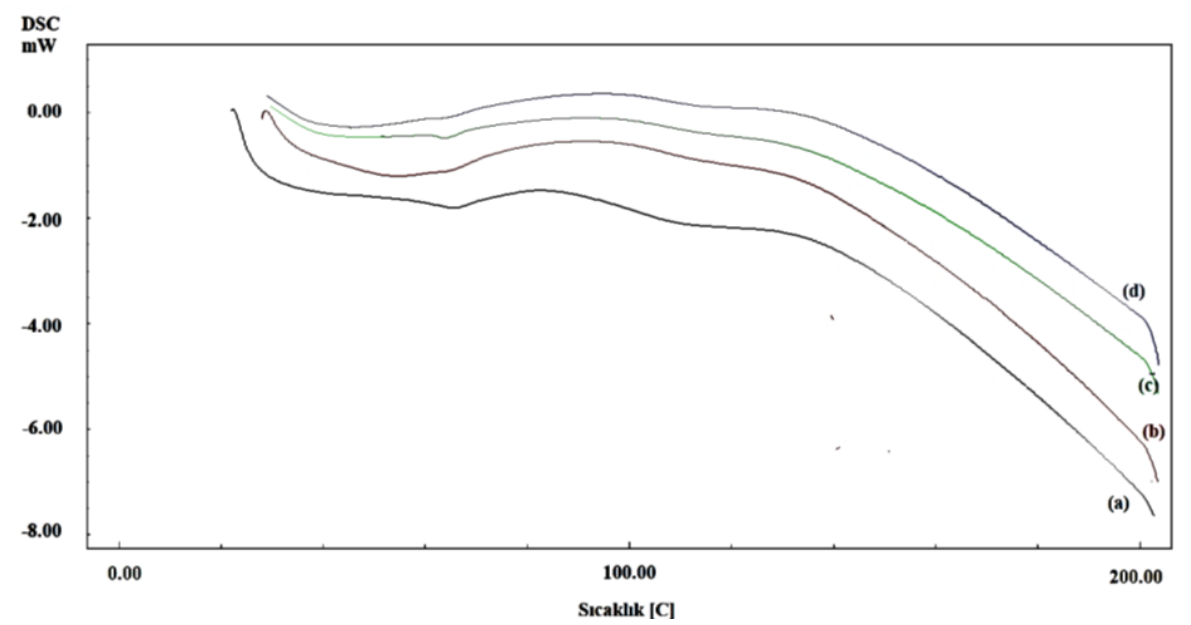

Şekil 5. DSC termogramları a) $\mathrm{P}(\varepsilon-\mathrm{CL}-c o-\mathrm{MMA})$, b) $\mathrm{P}(\varepsilon-\mathrm{CL}-c o-\mathrm{MMA}) / 3 \% \mathrm{MMT}$, c) $\mathrm{P}(\varepsilon-\mathrm{CL}-c o-$ MMA)/ 6\%MMT,d) P( $\varepsilon$-CL-co-MMA) /15\%MMT

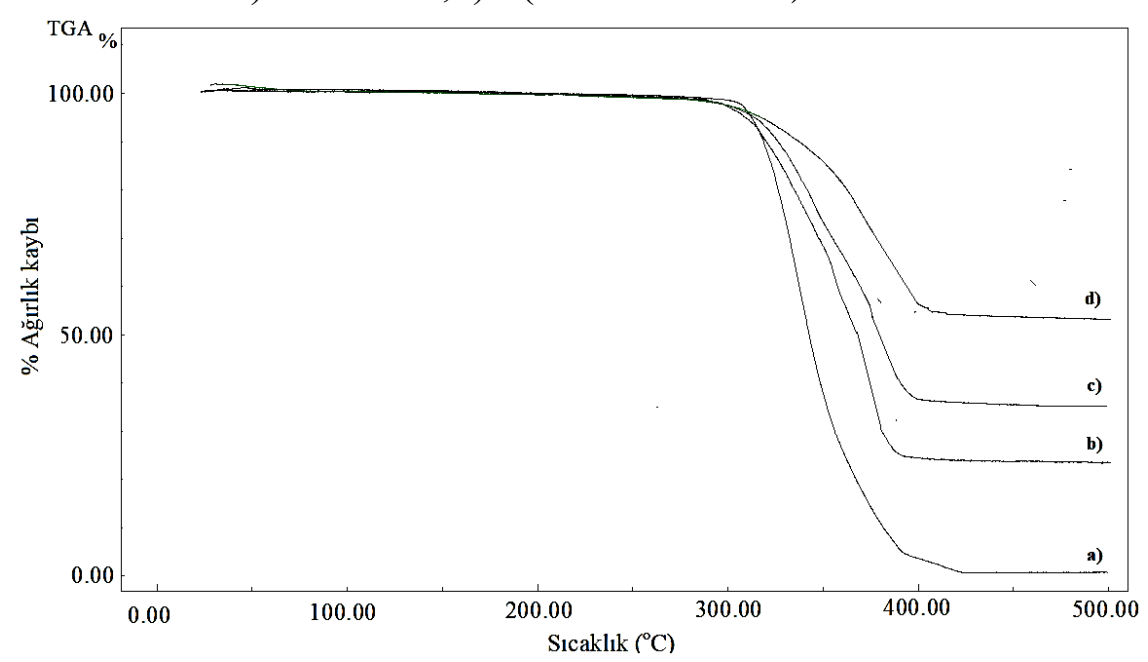

Şekil 6. TGA eğrileri a) $\mathrm{P}(\varepsilon-\mathrm{CL}-c o-\mathrm{MMA})$, b) $\mathrm{P}(\varepsilon-\mathrm{CL}-c o-\mathrm{MMA}) / 3 \% \mathrm{MMT}$, c) $\mathrm{P}(\varepsilon-\mathrm{CL}-c o-$ MMA) $/ 6 \% \mathrm{MMT}, \mathrm{d}) \mathrm{P}(\varepsilon-\mathrm{CL}-c o-\mathrm{MMA}) / 15 \% \mathrm{MMT}$

Çizelge 1. $\mathrm{P}(\varepsilon$-CL-co-MMA) ve kompozitlerin TGA ve DSC sonuçları

\begin{tabular}{|c|c|c|c|c|}
\hline Polimer & $\mathbf{T}_{\mathrm{g}}\left({ }^{\circ} \mathbf{C}\right)$ & $\mathbf{T}_{\text {başlangiç }}\left({ }^{\circ} \mathrm{C}\right)$ & $\mathrm{T}_{\text {son }}\left({ }^{\circ} \mathrm{C}\right)$ & 500 \%C'de \% Atık \\
\hline $\mathrm{P}(\mathcal{E}-\mathrm{CL}-c o-\mathrm{MMA})$ & 105 & 306 & 390 & 2 \\
\hline $\mathrm{P}(\varepsilon-\mathrm{CL}-c o-\mathrm{MMA}) / 3 \% \mathrm{MMT}$ & 110 & 308 & 397 & 36 \\
\hline $\mathrm{P}(\varepsilon-\mathrm{CL}-c o-\mathrm{MMA}) / 6 \% \mathrm{MMT}$ & 119 & 315 & 398 & 45 \\
\hline $\mathrm{P}(\varepsilon-\mathrm{CL}-c o-\mathrm{MMA}) / 15 \% \mathrm{MMT}$ & 125 & 340 & 401 & 58 \\
\hline
\end{tabular}

\section{Polimerlerin Empedans Analizör Uygulamaları}

\section{Dielektrik sabiti ve dielektrik kayıp özellikler}

$\mathrm{Bu}$ aşamada, sentezlenen katkısız $\mathrm{P}(\varepsilon-\mathrm{CL}-c o-\mathrm{MMA})$ ve kompozitlerin dielektrik ve iletkenlik değerleri incelenmiştir. Bunun amaçla 0,1 gr tartılan toz halindeki kopolimerler, yaklaşık 5 ton basınç uygulanarak disk haline getirildi ve kumpas ile disk kalınlığı ölçüldü. Diskin yüzeyi gümüş boya ile boyandı. Saf kopolimerin ve MMT ile farklı yüzdelerde katkılanmış kompozitlerin elektriksel ölçümleri alınmıştır. Empedans analizörle farklı frekans ve sıcaklıklarda kapasitans (Cp) ölçümleri, farklı frekanslarda ise, dielektrik kayıp (DF), kondüktans (Gp), susseptans (B) ve empedans (Z) parametrelerinin ölçümleri yapıldı. Bu ölçümlerden gerekli formüller yardımı ile dielektrik sabiti $\left(\varepsilon^{\prime}\right)$, dielektrik kayıp $\left(\varepsilon^{\prime \prime}\right)$, iletkenlik $\left(\sigma_{\mathrm{ac}}\right)$ değerleri hesaplandı. Ölçümlerde frekans aralığı $100 \mathrm{~Hz}$ ile $10 \mathrm{kHz}$, sıcaklık ise $298^{\circ} \mathrm{K}$ ile $423^{\circ} \mathrm{K}$ arasında yapılmıştır. Ölçülen Cp ve DF parametresi ile sırası ile dielektrik 
sabiti ve dielektrik kayıp faktör aşağıda verilen formüller yardımı ile hesaplanmıştır (Biryan, 2019; Rajendran ve ark., 2010).

$$
\begin{aligned}
& \varepsilon^{\prime}=\text { Cp. } \frac{d}{\epsilon_{0} A} \\
& \varepsilon^{\prime \prime}=\varepsilon^{\prime} . \mathrm{DF}
\end{aligned}
$$
A: Numunenin alanı $\left(\mathrm{m}^{2}\right)$
$\varepsilon^{\prime}$ : Dielektrik sabiti
$\mathrm{C}$ : Numunenin kapasitansi(F)
$\varepsilon^{\prime \prime}:$ Dielektrik kayıp
d: Numunenin çap1 (m)
$\varepsilon_{0}$ : Boşluğun dielektrik sabiti $\left(8.85 \times 10^{-12} \mathrm{~F} / \mathrm{m}\right)$

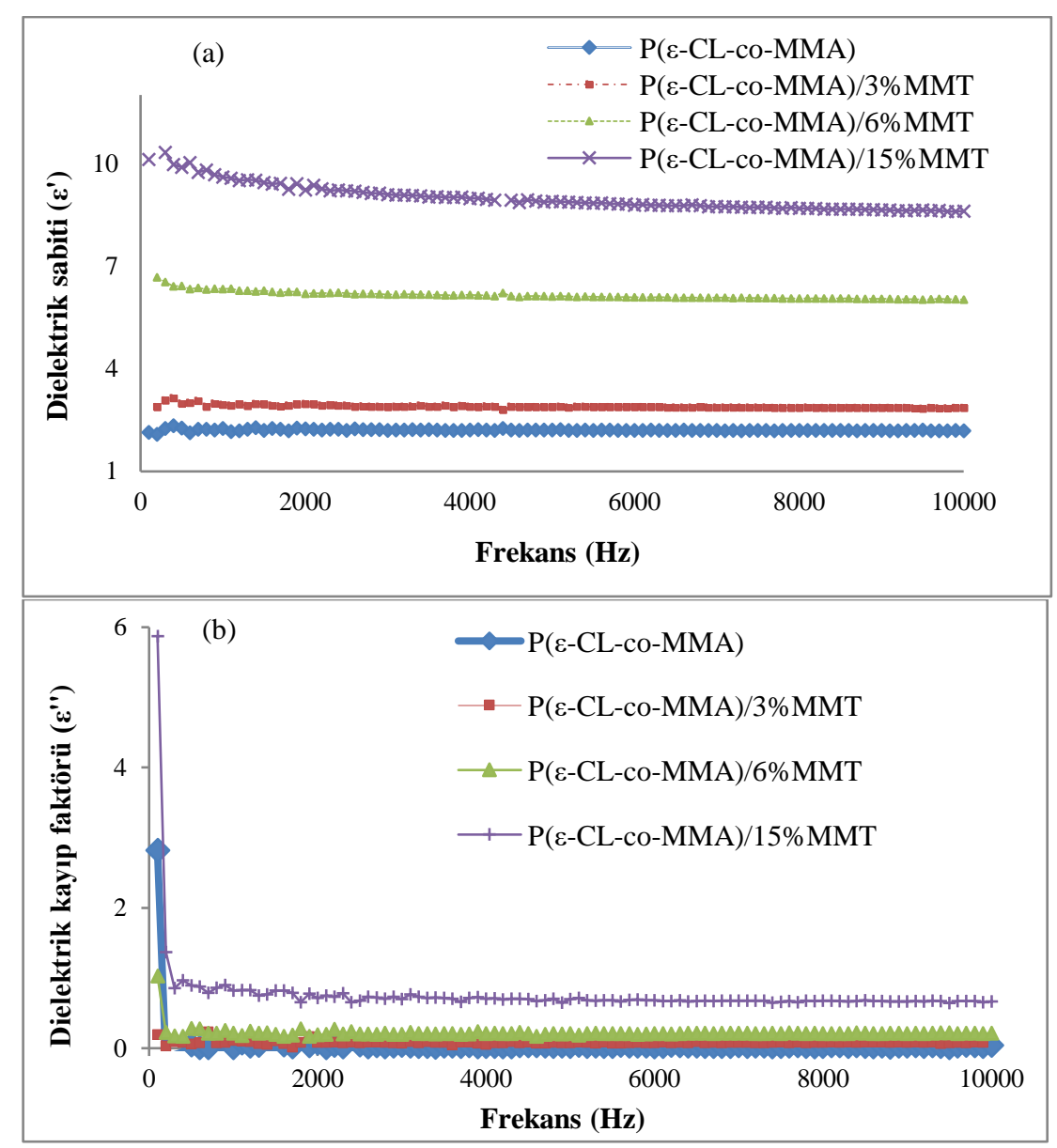

Şekil 7. P(ع-CL-co-MMA) ve \%MMT kompozitlerinin a) frekans ile dielektrik sabitlerindeki değişimi, b) frekans ile dielektrik kayıp faktör değişimi

Şekil 7 (a) ve Şekil 7(b)' de hesaplanan dielektrik sabiti değerleri; frekansın ve sıcaklığın bir fonksiyonu olarak karşılaştırmalı olarak grafiğe geçirilmiştir. Kopolimerlerin dielektrik sabitlerinin artan frekansla azaldığı, (Ayaz ve ark., 2012) yine aynı şekilde dielektrik kayıp değerlerinin de artan frekansla azaldığı görülmüştür (Zhang ve ark., 2007; Belakere ve ark., 1992). Frekans arttıkça dipollerin etkisi arttığ için polarizasyon oluşmuş ve dielektrik sabiti değerinde azalma gözlenmiştir. Çünkü o bölgede yüzeysel bir polarizasyon oluşmuştur (Belakere ve ark., 1992). Bununla beraber farklı bir yorum olarak şu sonuca varılmıştır. \%3, \%6 ve \%15 oranlarındaki MMT kompozitlerinde, montmorillonitin oranı arttıkça dielektrik sabitinde de artış meydana geldiği görülmüştür. Bu da; kil taneciklerinin, kopolimerler üzerindeki ölçümlere olan etkisinin, istenen yönde olduğunu kanıtlamaktadır. $1 \mathrm{kHz}{ }^{\prime}$ de; katkılanmamış $\mathrm{P}\left(\varepsilon\right.$-CL-co-MMA) kopolimeri için $\varepsilon^{\prime}=2.19$ iken, \%3 MMT için $\varepsilon^{\prime} ; 2.86, \% 5$ MMT için $\varepsilon^{\prime} ; 6.32, \% 15$ MMT için $\varepsilon^{\prime} ; 8.6$ olduğunu ve artışın gerçekleştiğini açıkça görebiliriz. Bu artışlar önemli 
sıçramalardır. Polimer/MMT dipol kısmının varlığına bağlı olarak artan dipollerin oryantasyonu ve ara yüzey polarizasyonun gerçekleşmesine bağlanabilir (Pihtili ve ark., 2020; Ilangovan ve ark., 2017; Ilangovan ve ark., 2016). Bu da inorganik maddenin polimerde homojen olarak karıştığını göstermektedir (Abd El-Kader ve ark., 2008). Ayrıca, bu artışın sebebi artan polar yapı ve iyonların ışınlaması sayesinde metallerin polimere bağlanması ile de açıklanabilir. Bunun yanında dielektrik kayıpların değerlerinin de doplama ile arttığı görüldü (Singh ve ark., 2010). Farklı yüzdelerdeki polimer örneklerinin artan frekans ile dielektrik kayıp faktörlerindeki değişim oranı, bütün örnekler için birbirine oldukça yakın değerdedir.

Şekil 8' de katkısız P(E-CL-co-MMA) kopolimerinin sıcaklık ile yapılan ölçümlerde dielektrik sabiti değerlerinin sıcaklıkla birlikte hızla arttığı görüldü. Uygulanan sıcaklıkla beraber polimerdeki yük hareketliliği artmış ve polimer moleküllerindeki segmentlerde polarlaşma meydana gelmiş olabileceğini söyleyebiliriz. Ayrıca, polimerlerin camsı geçiş sıcaklıklarına ulaştığı noktalarda ani artmalar meydana gelmiştir.

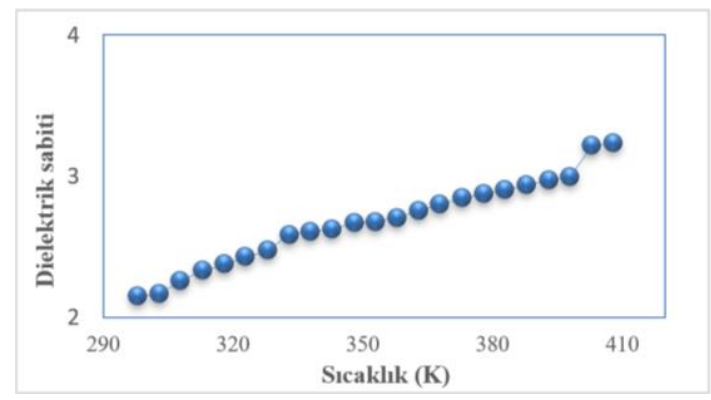

Şekil 8. Katkısız P(ع-CL-co-MMA) kopolimerinin dielektrik sabitinin sıcaklık ile değişimi

\section{AC iletkenlik}

AC iletkenlik ölçümleri iletim mekanizması için çok önemlidir. AC ölçümleri içinde yer alan kondüktans $\left(\mathrm{G}_{\mathrm{p}}\right)$ parametresinden aşağıdaki formül yardımı ile iletkenlik $\left(\sigma_{\mathrm{ac}}\right)$ değerleri hesaplanmıştır (Rajendran ve ark., 2010).

$\boldsymbol{\sigma}_{\mathrm{ac}}=\mathrm{G}_{\mathrm{p}} \cdot \frac{\mathrm{d}}{\mathrm{A}}$

Katkısız kopolimer ve polimer/MMT kompozitlerinin iletkenlik ölçümleri frekansın bir fonksiyonu olarak grafiğe geçirilmiştir. Frekans arttıkça, iletkenlik değerlerinde de artış meydana geldiği gözlenmiştir. Camsı geçiş sıcaklığının üzerinde, polimerik zincirler önemli bir şekilde hareketlilik kazanır. Bu nedenle, serbest iyonlar bu yapı içinde çok daha kolaylıkla iletilebilirler. $\mathrm{T}_{g}{ }^{\prime}$ nin üzerinde iyonik hareketlilik artmaktadır ve dolayısıyla iletkenlik yükselmektedir (Alkan, 2011). İletkenliğe etki eden diğer faktörler konjugasyon uzunluğu, doplama seviyesi ve anizotropi olarak siralanabilir. Konjugasyon uzunluğu, zincir konjugasyon defektleri arasındaki ortalama mesafedir (Akın, 2010; Roth ve ark., 1989). P(ع-CL-co-MMA) kopolimerinin, montmorillonit ile doplama yardımı ile daha büyük bir iletkenliğe ulaştıkları gözlenmiştir. Bu iletkenlik, metallerin gösterdiği iletkenliğe yakındır (Şen, 2007;

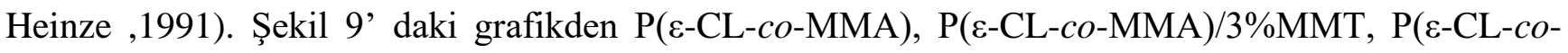
MMA $/ 6 \%$ MMT ve $\mathrm{P}(\varepsilon$-CL-co-MMA $/ 15 \% \mathrm{MMT}$ kompozitlerinin frekans ile iletkenliklerindeki değişimleri verilmiştir. $\mathrm{P}(\varepsilon-C L-c o-M M A)$ için $2 \mathrm{kHz}$ de $\sigma_{\mathrm{ac}}$ değeri; -8.61 S/cm iken, P(E-CL-coMMA)/15\%MMT için bu değer $-7.97 \mathrm{~S} / \mathrm{cm}$ olmuştur. Grafikten iletkenliğin; frekans arttıkça ve katkılama ile artış gösterdiği anlaşılmaktadır. Frekans ile artışa sebep olarak; uygulanan frekans bölgesinde $(100 \mathrm{~Hz}-10 \mathrm{kHz})$ elektron ve atomların elektriksel alanın etkisi ile yönelmesi sonucu elektriksel polarizasyon oluşmaktadır. Böylece oluşan dipoller, polimer yüzeyinde elektriksel bir yük birikimine neden olurlar (Yakuphanoglu ve ark., 2005; Ayaz, 2012). 


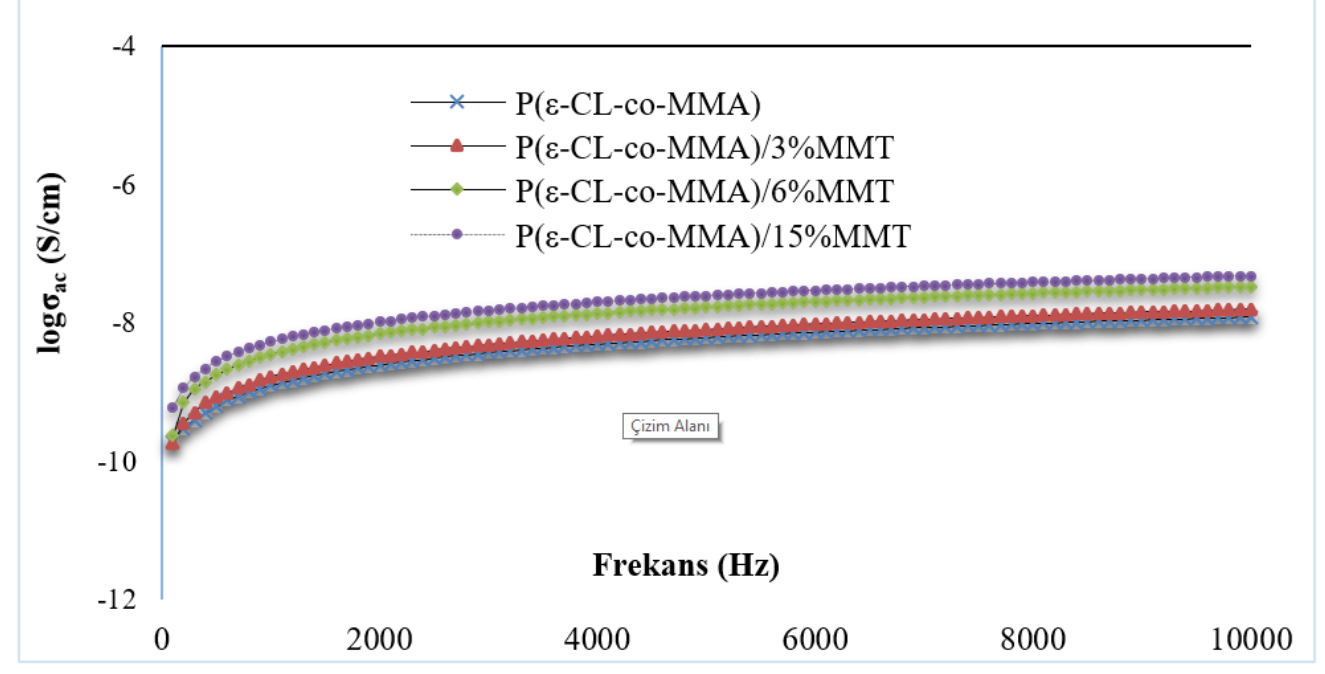

Şekil 9. $\mathrm{P}(\varepsilon-\mathrm{CL}-c o-\mathrm{MMA})$ ve \%MMT kompozitlerinin $\log \sigma_{\mathrm{ac}}$ 'nın frekans ile değişimi

\section{Elektriksel Susseptans ve Empedans}

Susseptans (B); bir devreden geçen akımın iletme kapasitesinin nasıl değiştiğinin bir ölçüsü olarak bilinmektedir. Başka bir tanıma göre susseptans; akım ve gerilim dalgalanması ile oluşan, devre veya sistemde depo edilen enerjiyi ifade eder. Susseptansın birimi Siemens'tir. Çok telli iletişim kablolarında önemli bir role sahiptir ve ölçümünün temeli paralel kapasitansa (Cp) dayanır. Susseptans değerleri, artan frekans ve sicaklık ile daha büyümektedir (Zhang ve ark., 2007). Empedans (Z); iç direnç, alternatif akım direnci), bir sisteme gerilim uygulandığında; devrenin akıma geçiş için sunduğu direncin ölçüsü olarak düşünülür ve bu değer, materyallerin alternatif elektrik akım uyaranına tepkisinden ortaya doğar (Yakuphanoglu ve ark., 2004). Empedans birimi “ohm” dur ve Z ile gösterilir. Kabuk iletkeninin sinırlı iletkenliğinin sonucu olarak, topraklama döngüsü içinde toprak empedansı oluşur. Farklı cihazlar topraklama empedans bağlantısı nedeniyle elektromanyetik girişime neden olabilirler. Empedans $(Z)$ ölçümü kompleks malzemelerde bu sürecin yük taşınması karakterize ve gerçekleştirmek için güçlü tekniklerden biridir (Dinesh ve ark., 2010). Sentezlenen kopolimer ve kompozitlerin; susseptans (B) ve empedans (Z) ölçümleri $100 \mathrm{~Hz}-10 \mathrm{kHz}$ arasında gerçekleştirildi. Bu değerler frekansın bir fonksiyonu olarak grafiğe geçirildi. Şekil 10' da verilen grafikte bütün polimerlerin B değerlerinin frekans ile doğrusal bir şekilde arttı̆̆1 gözlendi (Yakuphanoğlu ve ark., 2005; Yakuphanoğlu ve ark., 2004). Empedans ölçümlerinde ise artan frekans ile Z değerinin azaldığ gözlenmiştir. Şekil 11' deki grafik bu azalışı destekler niteliktedir. $B^{\prime}$ deki artmalar yönelme polarizasyonun etkisiyle oluşmaktadır. Empedanstaki azalma ise, artan segmantal hareketliliğin (bağ kırılması, serbest hacmin artması) verdiği hasar ile ilgili olabilir (Dinesh ve ark., 2010). Polimerlerin 1kHz'deki elektriksel sonuçları Çizelge 2' de verilmiştir. 


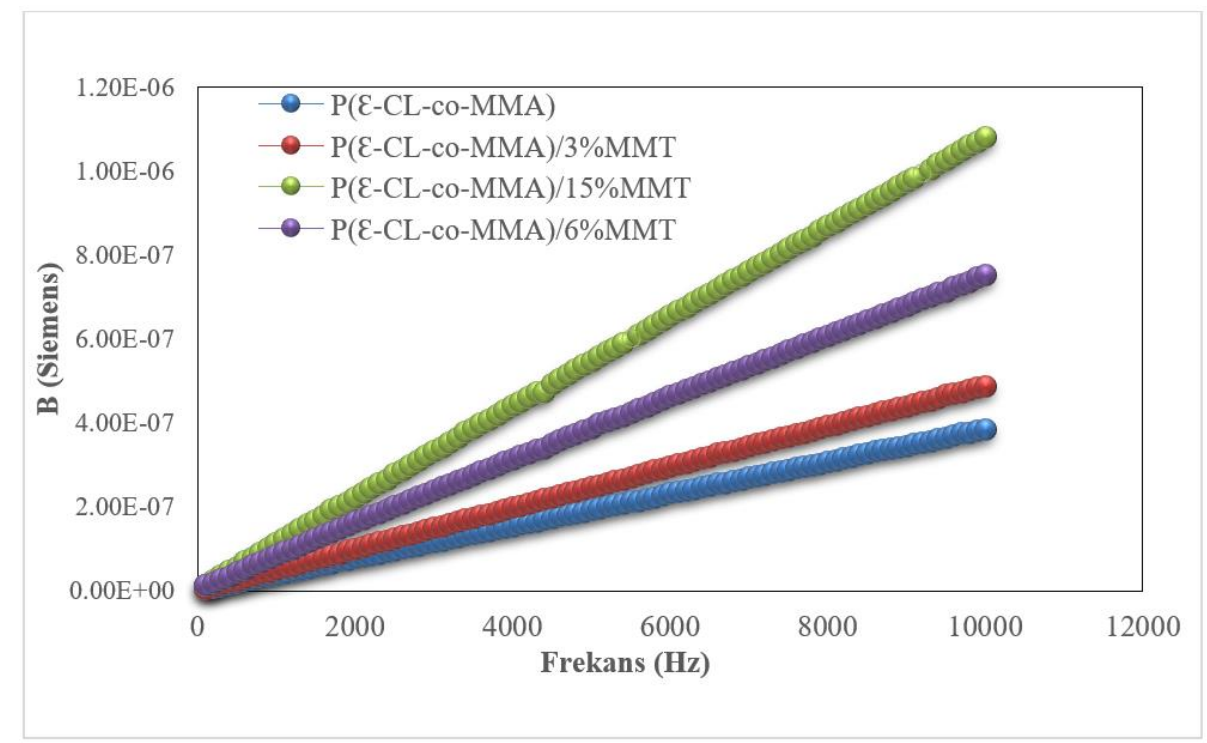

Şekil 10. $\mathrm{P}(\varepsilon$-CL-co-MMA) ve \%MMT kompozitlerinin B değerlerinin frekans ile değişimi

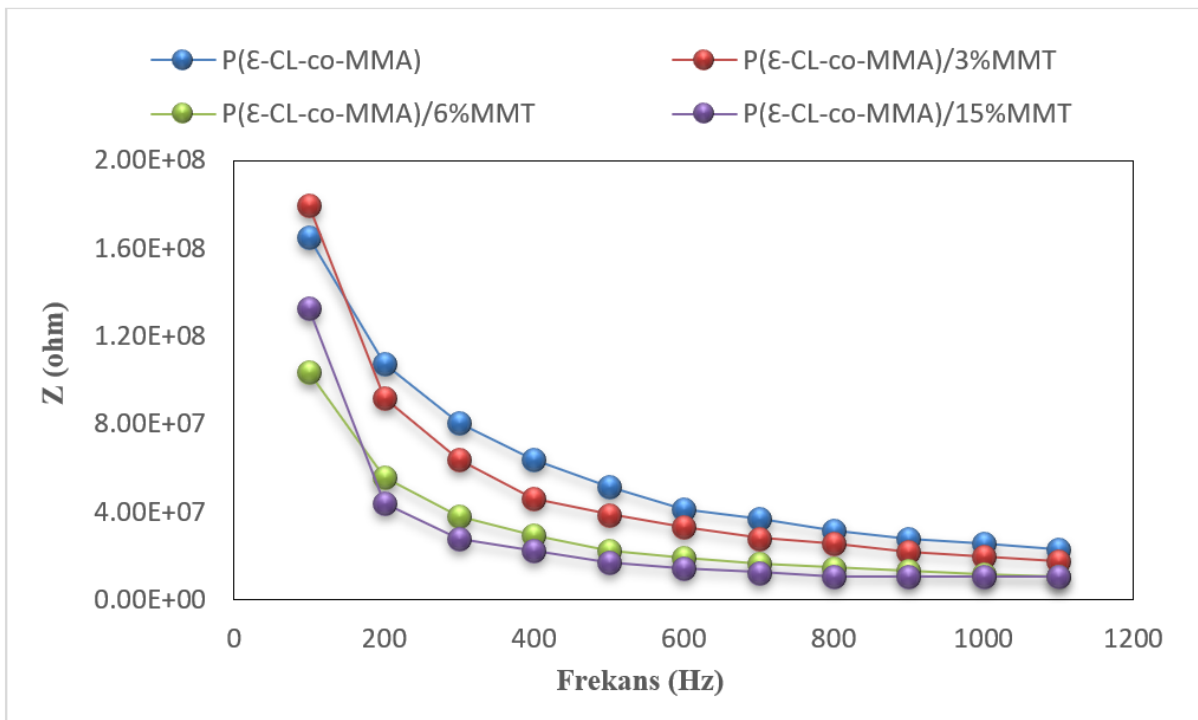

Şekil 11. $\mathrm{P}(\varepsilon-\mathrm{CL}-c o-\mathrm{MMA})$ ve \%MMT kompozitlerinin $\mathrm{Z}$ değerlerinin frekans ile değişimi

Çizelge 2. $\mathrm{P}(\varepsilon-\mathrm{CL}-\mathrm{co}-\mathrm{MMA})$ ve kompozitlerin $1 \mathrm{kHz}$ 'deki elektriksel empedans analiz değerleri

\begin{tabular}{cccccc}
\hline Polimer & $\boldsymbol{\varepsilon}^{\prime}$ & $\boldsymbol{\varepsilon}^{\prime \prime}$ & $\boldsymbol{\sigma}_{a c}$ & $\mathbf{B}$ & $\mathbf{Z}$ \\
\hline $\mathrm{P}(\varepsilon-$-CL-co-MMA $)$ & 2.25 & 0.064 & -8.862 & $3.55 \mathrm{E}-08$ & $3.17 \mathrm{E}+07$ \\
$\mathrm{P}(\varepsilon-$-CL-co-MMA $) / 3 \%$ MMT & 2.95 & 0.091 & -8.788 & $5.04 \mathrm{E}-08$ & $2.57 \mathrm{E}+07$ \\
$\mathrm{P}(\varepsilon$-CL-co-MMA)/6\%MMT & 6.37 & 0.215 & $-8,459$ & $8.40 \mathrm{E}-08$ & $1.48 \mathrm{E}+07$ \\
$\mathrm{P}(\varepsilon-$-CL-co-MMA $) / 15 \% \mathrm{MMT}$ & 9.63 & 0.822 & -8.270 & $1.13 \mathrm{E}-07$ & $1.09 \mathrm{E}+07$ \\
\hline
\end{tabular}

\section{SEM Mikroskop Analizi}

Kütlece farklı oranlarda \%3, \%6, \%15 MMT (montmorillonit) ile hazırlanan polimer/MMT kompozitlerin yüzeylerinin morfolojik analizleri taramalı elektron mikroskobuyla (SEM) yapılmış olup farklı büyütmelerdeki (SEM) resimleri Şekil 12' de verilmiştir. SEM analizleri Hitachi S-3500 marka taramalı elektron mikroskobu ile gerçekleştirilmiştir. SEM görüntüleri incelendiğinde; kopolimerin saf halinin düzgün, pürüzsüz ve homojen bir yapıya sahip olduğu açıktır. Kompozit yapılarında ise polimer molekülleri arasında dağılmış MMT' nin parçalı ve tabakalı yapısı görülmektedir. MMT miktarı arttıkça polimerin düzgün yapısının bozularak tabaka görünümünün arttığı tespit edilmiştir. Genel olarak montmorillonit partiküllerinin polimer molekülleri arasında homojen olarak dağıldığ 1 görülmektedir. 

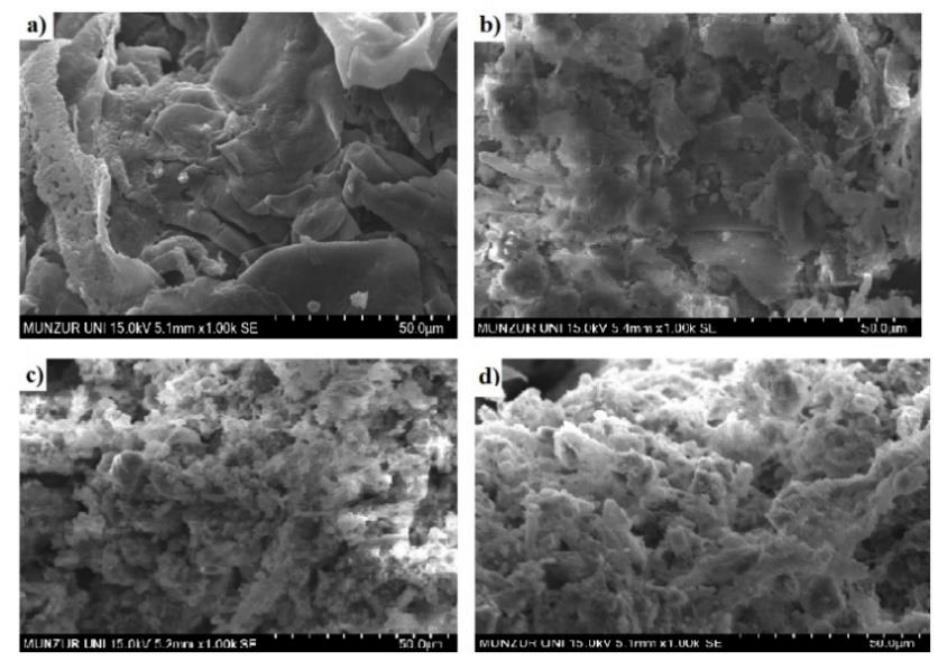

Şekil 12. a) $\mathrm{P}(\varepsilon-\mathrm{CL}-c o-\mathrm{MMA}), \mathrm{b}) \mathrm{P}(\varepsilon-\mathrm{CL}-c o-\mathrm{MMA}) / 3 \% \mathrm{MMT}$, c) $\mathrm{P}(\varepsilon-\mathrm{CL}-c o-\mathrm{MMA}) / 6 \% \mathrm{MMT}$, d)P( $(\varepsilon-$ CL-co-MMA)/15\%MMT

\section{SONUÇ}

$\mathrm{Bu}$ çalışmada metil metakrilat monomeri kullanarak, ATRP ile P(ع-CL-co-MMA) kopolimeri sentezlenmiştir. İnorganik materyal olan montmorillonit (bentonit) ile farklı oranlarda kompozitleri hazırlanıp, bunların polimer içindeki dağılımları SEM cihazı ile incelenmiştir. Sentezlenen polimerlerin termal davranışları incelenip, elektriksel özelikleri araştırılmıştır. Verilere göre montmorillonit polimer içinde homojen olarak dağılmış ve polimerin yapısında bulunan boşluklara yerleşmiştir. Bentonit ile katkılanmış polimerlerin elektriksel özellikleri; saf haldeki polimerlerin elektriksel özelliklerine göre daha yüksek değerlerde çıkmıştır. Bu da, inorganik materyallerin polimerlerin elektriksel özelliklerinde büyük bir artış gösterdiğini kanıtlamaktadır. Sonuç olarak; Türkiye'nin yüksek bentonit rezervlerine sahip olması nedeniyle, polimerlere dolgu malzemesi olarak bentonitin kullanılması, ileri teknoloji alanlarında büyük önem taşıyacağı düşünülmektedir. Sanayinin birçok alanında bentonit katkılı kompozitlerin üretimi bu maddenin özelliklerinin iyileşmesini sağladığından, daha sağlam malzemelerin üretileceği düşünülmektedir. Hem ekonomik olan hem de polimere birçok üstün özellik kazandıran polimer/kil kompozitlerinin öneminin her alanda giderek artacağ 1 düşünülmektedir. $\varepsilon$-CL içerikli polimer/kil kompozitlerinin; elektronik cihazlarda, tıp ve farmokoloji alanında, havacılık sanayisinde, otomobil endüstrisinde ve inşaat malzemelerinde kullanılması olası olacağı düşünülmektedir.

\section{TEŞEKKÜR}

Bu çalışmada mali destek, Munzur Üniversitesi Bilimsel Araştırma Projeleri Koordinasyon Birimi tarafından MFMUB017-10 nolu proje ile sağlanmıştır.

\section{Çıkar Çatışması}

Makale yazarları arasında herhangi bir çıkar çatışması yoktur.

\section{Yazar Katkısı}

Güzin Pıhtılı: Yazma - Orijinal Taslak, Araştırma, Kavramsallaştırma, Metodoloji, Yazılım; Gülben Torğut: Araştırma, Analiz 


\section{KAYNAKLAR}

Abd El-kader FH, Osman WH, Mahmoud KH, Basha MAF, 2008. Dielectric investigations and ac conductivity of polyvinyl alchol films doped with europium and terbium chloride. Physica B, 403: 3473-3484.

Akın H, 2010. İletken polimerlerin in sitü ESR tekniği ile incelenmesi, G.Y.T.E., Mühendislik ve Fen Bilimleri Enstitüsü, Yüksek Lisans Tezi (Basılmış).

Alkan Ü, 2011. Polimer kompozitlerin mekanik ve elektrik özelliklerinin kararlı hale getirici ve yıpratıc1 faktörlerin etkisi altında incelenmesi, Yıldız Teknik Üniversitesi, Fen Bilimleri Enstitüsü, Doktora Tezi (Basılmış).

Alparslan M, 2013. Polimer-kil kompozitlerinin sentezi ve karakterizasyonu, Bozok Üniversitesi Fen Bilimleri Enstitüsü, Yüksek Lisans Tezi (Basılmış).

Ayaz N, 2012. Benzil metakrilat ile 2-okso-2H-kromen-7il-metakrilat kopolimerlerinin sentezi ve karakterizasyonu, Fırat Üniversitesi Fen Bilimleri Enstitüsü, Doktora Tezi (Basılmış).

Ayaz N, Bezgin F, Demirelli K, 2012. Polymers based on methacrylate bearing comumarin side group: Synthesis via free radical polymerization, monomer reactivity ratios, dielectric behavior and thermal stabilities. International Scholarly Research Notices, 2012: 352759.

Belakere NN, Misra SCK, Ram MK, Rout DK, Gupta R, Malhotra BD, Chandra S, 1992. Interfacial polarization in semiconducting polypyrrole thin films. Journal of Physics: Condensed Matter, 4: 5747-5756.

Biryan F, 2019. Kalkon ve hidroksil yan grupları içeren yeni metakrilat polimerinin sentezi, karakterizasyonu, termal ve elektriksel davranışları. Afyon Kocatepe Üniversitesi Fen ve Mühendislik Bilimleri Dergisi, 19: 544-555.

Çalımlı A, 2010. Nanokil-polimer kompozitlerinin sentez ve karakterizasyonu, Ankara Üniversitesi Bilimsel Araştırma Projesi. (Basılmış).

Çankaya N, Sökmen Ö, 2016. Kitosan-kil biyonanokompozitleri. Politeknik Dergisi, 19: 283-295.

Dinesh P, Renukappa NM, Siddaramaiah, 2010. Impedance and susceptance characterization of multiwalled carbon nanotubes with high density polyethylene-carbon black nanocomposites. Integrated Ferroelectrics, 116:128-136.

Giannelis EP, 1996. Polymer layered silicate nanocomposites. Advanced Materials, 8:29-35.

Güven O, 2010. Farklı bentonit tipleri ile stiren bütil akrilat esaslı nanokompozitlerin üretimi ve karakterizasyonu, İstanbul Teknik Üniversitesi Fen Bilimleri Enstitüsü, Yüksek Lisans Tezi (Basılmış).

Heinze J, 1991. Electrochemistry of conducting polymerrs. Synthetic Metals, 41:2805.

Ilangovan P, Sakvai MS, Kottur AB, 2016. An electrically active methacrylate based polymer reinforced with $\mathrm{ZnO}$ - synthesis, characterization and dielectric properties. Materials Letters, 183:240-243.

Ilangovan P, Sakvai MS, Kottur AB, 2017. Synergistic effect of functionally active methacrylate polymer and $\mathrm{ZnO}$ nanoparticles on optical and dielectric properties. Materials Chemistry and Physics, 193:203-211.

İyibakanlar G, Oktay A, 2007. Bazı polimerlerin dielektrik özelliklerinin frekansla değişimlerinin incelenmesi. Havacılık ve Uzay Teknolojileri Dergisi, 3: 11-19.

Neamen DA, 1997. Semiconductor physics and devices 2nd ed, Mc Graw-Hill, 420-450, 517-523, New York.

Pihtili G, Torğut G, Biryan F, 2020. Electrical properties of two-armed poly(E-CL-co-BMA) composites filled with bentonite. Journal of Polymer Research, 27:156. 
Rajendran S, Ramesh Prabhu M, 2010. Effect of different plasticizer on structural and electrical properties of PEMA-based polymer electrolytes. Journal of Applied Electrochemistry. 40: 327332.

Ravindra Reddy T, Kaneko S, Endo T, Lakshmi Reddy S, 2017. Spectroscopic characterization of bentonite. J Laser Opt Photonics, 4:171.

Roth S, Bleier H, Pukacki W, 1989. Faraday Discuss. Chemical Society ,88: 223-233.

Singh D, Singh NL, Qureshi A, Kulriya P, Tripathi A, Avasti DK, Gulluoglu AN, 2010. Radiation induced modification of dielectric and structural properties of $\mathrm{Cu} / \mathrm{PMMA}$ polymer composites. Journal of Non-Crystalline Solids, 356: 856-863.

Symth CP, 1955. Dielectric behaviour and structure. McGraw-Hill, 52: 202-215, New York.

Şen S, 2007. Polivinilferrosen/polipirol kompozitlerinin sentezi ve karakterizasyonu, Süleyman Demirel Üniversitesi Fen Bilimleri Enstitüsü, Doktora Tezi (Basılmış).

Tareev B, 1975. Physics of dielectric materials. Mir Publishers, Moscow.

Usuki A, Kojima Y, Kawasumi M, Okada A, Fukushima Y, Kurauchi T, Kamigaito O, 1993. Synthesis of nylon 6-clay hybrid. Journal of Materials Research, 8: 1179-1184.

Xu Y, Ren X, Hanna MA, 2006. Chitosan/clay nanocomposite film preparation and characterization. Journal of Applied Polymer Science, 99:1684-1691.

Yakuphanoglu F, Okutan M, Zhuang Q, Han Z, 2005. The dielectric spectroscopy and surface morphology studies in a new conjugated polymer poly(benzobisoxazole-2,6-diylvinylene). Physica B: Condensed Matter, 365:13-19.

Yakuphanoglu F, Yoo YT, Okutan M, 2004. An impedance spectroscopy study in poly(butylene adipate) ionomers. Annalen der Physik, 13: 559-568.

Yang T-I, Kofinas P, 2007. Dielectric properties of polymer nanoparticle composites, Polymer, 48: 791798.

Zhang C, Li CJ, Zhang G, Ning XJ, Li CX, Liao H, Coddet C, 2007. Ionic conductivity and its temperature dependence of atmospheric plasma-sprayed yttria stabilized zirconia electrolyte. Materials Science and Engineering B, 137:24-30. 